Yahya Ahmadipour*, Julie-Inga Krings, Laurèl Rauschenbach, Oliver Gembruch, Mehdi Chihi, Marvin Darkwah Oppong, Daniela Pierscianek, Ramazan Jabbarli, Ulrich Sure and Nicolai El Hindy

\title{
The influence of subventricular zone involvement in extent of resection and tumor growth pattern of glioblastoma
}

https://doi.org/10.1515/iss-2020-0011

Received April 9, 2020; accepted July 7, 2020; published online August 27, 2020

\section{Abstract}

Objectives: Isocitrate dehydrogenase (IDH1/2) mutations and 06-alkylguanine DNA methyltransferase (MGMT) promoter methylations are acknowledged survival predictors in patients with glioblastoma (GB). Moreover, tumor growth patterns like multifocality and subventricular zone (SVZ) involvement seem to be associated with poorer outcomes. Here, we wanted to evaluate the influence of the SVZ involvement and the multifocal tumor growth on the extent of surgical resection and its correlation with overall survival (OS) and molecular characteristics of patients with GB.

Methods: Adult patients with primary GB who underwent surgery at our department between 2012 and 2014 were included. Preoperative magnetic resonance imaging findings were analyzed with regard to tumor location, presence of multifocality and SVZ involvement. The extent of surgical resection as well as clinical and molecular parameters was collected from electronic patient records. Univariate and multivariate analyses were performed.

Results: Two hundred eight patients were retrospectively analyzed, comprising 90 (43.3\%) female individuals with a mean age of $62.9( \pm 12.26)$ years and OS of 10.2 months $( \pm 8.9)$. Unifocal tumor location was a predictor for better OS with a

*Corresponding author: Yahya Ahmadipour, Department of Neurosurgery, University Hospitals Essen, Hufelandstrasse 55, 45122, Essen, Germany; German Cancer Consortium, Partner Site University Hospital Essen, Essen, Germany. Phone: +49 201723 1230, E-mail: yahya.ahmadipour@uk-essen.de. https://orcid.org/00000003-3759-8301

Julie-Inga Krings, Department of Neurosurgery, University Hospital Essen, Essen, Germany

Laurèl Rauschenbach, Oliver Gembruch, Mehdi Chihi, Marvin Darkwah Oppong, Daniela Pierscianek, Ramazan Jabbarli, Ulrich Sure and Nicolai El Hindy, Department of Neurosurgery, University Hospital Essen, Essen, Germany; German Cancer Consortium, Partner Site University Hospital Essen, Essen, Germany mean of 11.4 ( \pm 9.4$)$ months (vs. 8.0 [ \pm 7.4$]$ months, $p=0.008)$. Affection of the SVZ was also associated with lower surgical resection rates $(\mathrm{p}<0.001)$. SVZ involvement revealed with 7.8 $( \pm 7.0)$ months a significant worse OS [vs. $13.9( \pm 10.1)$ months, $\mathrm{p}<0.001]$. All six IDH1/2 wildtype tumors showed an unifocal location ( $\mathrm{p}=0.066)$. MGMT promoter methylation was not associated with multifocal tumor growth $(\mathrm{p}=0.649)$ or SVZ involvement $(\mathrm{p}=0.348)$. Multivariate analysis confirmed independent association between the SVZ involvement and OS ( $\mathrm{p}=0.001)$.

Conclusion: The involvement of the SVZ appears to have an influence on a lower resection rate of GB. This negative impact of SVZ on GB outcome might be related to lesser extent of resection, higher rates of multifocality and greater surgical morbidity but not inevitably to $I D H 1 / 2$ mutation and MGMT promoter methylation status.

Keywords: extent of resection; glioblastoma; multifocality; subventricular zone.

\section{Introduction}

Glioblastoma (GB) is the most common primary tumor of the central nervous system [1]. Currently, clinical management comprises surgical, chemotherapeutic and radiotherapeutic treatment approaches [2]. Despite tremendous research efforts, early tumor progression and tumor recurrence is a frequent event of GB, whereas the improvement of quality of life is one of the main aims for treatment. However, interindividual patient survival is heterogeneous, with some patients surviving for years [3]. Characteristics like age, clinical performance status, tumor location and molecular tumor markers have been identified as potential prognostic factors in patients with these tumors. Today, 06alkylguanine DNA methyltransferase (MGMT) promoter hypermethylation and isocitrate dehydrogenase (IDH1/2) mutations are important predictors of treatment response and patient survival, allowing a subclassification of patients with malignant gliomas [4-6]. 
Numerous preclinical and clinical reports suggest that only a subset of cancer cells within a tumor might be responsible for treatment failure $[7,8]$. These cells exhibit stem cell-like properties and are multipotent, proliferative, invasive and resistant to antiglioma treatment. Thus, brain areas with neuronal stem cell activity have early been associated with brain cancer development [9-12]. The subventricular zone (SVZ) is a brain area close to the lateral ventricles and besides the subgranular zone, which is the most important source of neurogenesis throughout adult life [13]. Preclinical studies demonstrate that neuronal stem cells of the SVZ are able to transform into GB [9-12]. Moreover, studies have shown a tendency for GB involving the SVZ to poorer outcome with early recurrence and multifocal tumor growth pattern [14-17]. Finally, there is growing evidence that the SVZ might be more susceptible to tumorigenesis than other brain areas. It is still discussed controversially whether neuronal stem cells are the cell of origin of malignant gliomas [18].

Based on a retrospective single-center cohort with consecutive GB cases, we aimed to analyze the influence of the SVZ involvement and other radiographic tumor growth patterns on overall survival (OS) of patients with GB, particularly with regard to their molecular characteristics.

\section{Patients and methods}

All adult patients ( $\geq 18$ years) with newly diagnosed GB treated at our department between January 2012 and December 2014 were reviewed retrospectively.

Histology was confirmed in all patients, and neuropathological specimen analysis was performed according to the World Health Organization Classification of Central Nervous System Tumors of 2016 [1]. This study was performed in accordance with the Declaration of Helsinki and was approved by the local ethics committee.

\section{Pathohistological assessment}

Following surgery, patients with a tumor tissue underwent an integrated morphologic and molecular diagnostic analysis at the Institute of Neuropathology at the University Hospital of Essen. 06-methylguanine-DNA methyltransferase promoter methylation was assessed by pyrosequencing. Isocitrate dehydrogenase analysis was performed via immunohistochemistry.

\section{Magnetic resonance imaging scans}

All patients received a preoperative contrast-enhanced magnetic resonance imaging scan to determine tumor extension and SVZ involvement. Tumor location was determined based on contrastenhanced T1-weighted sequences on axial and coronal images. Per

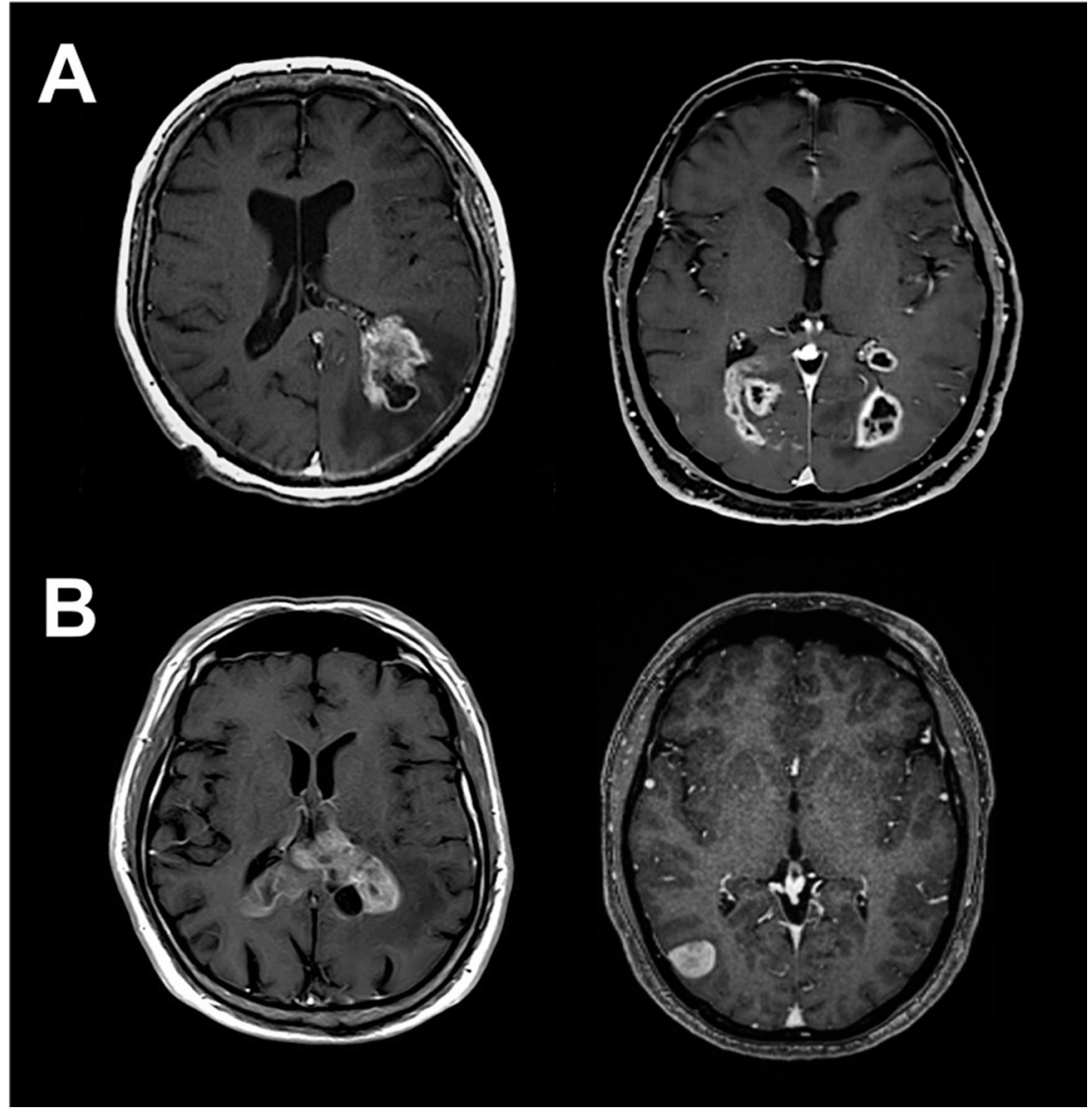

Figure 1: Representative MRI scans of patients with GB. (A) GB with unifocal (left) or multifocal (right) growth pattern. (B) GB with (left) or without (right) SVZ involvement. $M R I$, magnetic resonance imaging; $G B$, glioblastoma; SVZ, subventricular zone. 
Table 1: Characteristics different subgroups regarding to SVZ involvement.

\begin{tabular}{|c|c|c|c|c|}
\hline & Cases (n) & SVZ+ & SVZ- & $\begin{array}{l}\text { p- } \\
\text { Value }\end{array}$ \\
\hline Age years & $\begin{array}{c}\text { Mean=62.90 } \\
\pm 12.26\end{array}$ & $\begin{array}{r}62.96 \\
( \pm 12.91)\end{array}$ & $\begin{array}{r}62.80 \\
( \pm 11.22)\end{array}$ & 0.927 \\
\hline OS months & $\begin{array}{c}\text { Mean=10.18 } \\
\pm 8.86\end{array}$ & $\begin{array}{r}7.76 \\
( \pm 7.02)\end{array}$ & $\begin{array}{r}13.87 \\
( \pm 10.08)\end{array}$ & $<0.001$ \\
\hline $\begin{array}{l}\text { Two-year } \\
\text { survival }\end{array}$ & $\mathrm{n}=15$ & $3(20 \%)$ & $12(80 \%)$ & 0.001 \\
\hline $\begin{array}{l}\text { KPS } \\
\text { preoperative }\end{array}$ & Mean $=78.32 \%$ & $77.34 \%$ & $79.88 \%$ & 0.176 \\
\hline $\begin{array}{l}\text { KPS } \\
\text { postoperative }\end{array}$ & Mean $=72.93 \%$ & $70.86 \%$ & $76.25 \%$ & 0.047 \\
\hline $\begin{array}{l}\text { MGMT } \\
\text { methylated }\end{array}$ & $n=82,41 \%$ & $\begin{array}{r}46 \\
(56.1 \%)\end{array}$ & $\begin{array}{r}36 \\
(43.9 \%)\end{array}$ & 0.380 \\
\hline$I D H 1 / 2$ mutated & $\mathrm{n}=6,3.1 \%$ & $3(50 \%)$ & $3(50 \%)$ & 0.682 \\
\hline \multirow[t]{3}{*}{$\begin{array}{l}\text { Extent of resec- } \\
\quad \text { tion (EOR) }\end{array}$} & GTR $(n=97)$ & $\begin{array}{r}43 \\
(44.3 \%)\end{array}$ & $\begin{array}{r}54 \\
(55.7 \%)\end{array}$ & $<0.001$ \\
\hline & STR $(n=65)$ & $\begin{array}{r}47 \\
(72.3 \%)\end{array}$ & $\begin{array}{r}18 \\
(27.7 \%)\end{array}$ & \\
\hline & SB $(n=46)$ & $\begin{array}{r}38 \\
(82.6 \%)\end{array}$ & $8(17.4 \%)$ & \\
\hline \multirow[t]{2}{*}{ Multifocality } & Unifocal $(n=131)$ & $\begin{array}{r}65 \\
(49.6 \%)\end{array}$ & $\begin{array}{r}66 \\
(50.4 \%)\end{array}$ & $<0.001$ \\
\hline & $\begin{array}{c}\text { Multifocal } \\
\quad(n=77)\end{array}$ & $\begin{array}{r}63 \\
(81.8 \%)\end{array}$ & $\begin{array}{r}14 \\
(18.2 \%)\end{array}$ & \\
\hline
\end{tabular}

GB, glioblastoma; KPS, Performance Status Scale; OS, overall survival; SVZ, subventricular zone; STR, subtotal resection.

definition, multifocality was defined as the presence of two independent contrast-enhanced lesions in one or both hemispheres. SVZ involvement was assessed if the contrast-enhancing lesion contacted the lateral walls of the lateral ventricle. Examples are shown in Figure 1.

OS after GB surgery was the main endpoint of this study. Moreover, long-term survival was also addressed as two-year survival. Patients' age was assessed as continuous and dichotomous variables (with dichotomization at the cohort's mean age). Based on radiological reports, extent of resection (EOR) was evaluated in a categorical manner, where the cases were referred to the following three surgical groups: gross-total resection (GTR, with removal of the contrastenhancing tumor mass), subtotal resection (STR) and stereotactic biopsy (SB).

Table 2: Comparison of SVZ involvement and multifocality in relation to overall survival in months.

\begin{tabular}{lrrr}
\hline GB ( $\mathbf{n = 2 0 8 )}$ & Survival months & Std. deviation & p-Value \\
\hline Unifocal & 11.4 & \pm 9.4 & $\mathbf{0 . 0 0 8}$ \\
Multifocal & 8.0 & \pm 7.4 & \\
SVZ uninvolved & 13.9 & \pm 10.1 & $<0.001$ \\
SVZ involved & 7.8 & \pm 7.0 & \\
\hline
\end{tabular}

GB, glioblastoma; SVZ, subventricular zone.
SB was conducted using a Leksell Stereotactic System (Elekta, Stockholm, Sweden). In patients with microsurgical resection, a neuronavigation (Brainlab, Munich, Germany) was used, and 5-aminolevulinic acid was given to the patients prior surgery as a standard performance.

Postoperative treatment was planned individually, according to tumor diagnosis, age and clinical performance status. Preoperative and postoperative outcomes were assesses using the Karnofsky Performance Status Scale (KPS) before and up to four weeks after surgery, where KPS $\leq 70 \%$ was defined as poor clinical condition.

The following patient data were collected for further analysis: sex, age, preoperative and postoperative KPS values, EOR, IDH1/2 mutation and MGMT promoter methylation status and OS in months.

The associations of the SVZ involvement with other patients' characteristics were first analyzed in a univariate manner. Continuous variables were addressed with Pearson's linear correlation, the Student's t-test or the Mann-Whitney U tests, as appropriate. Associations between categorical variables were analyzed using the Chi-square test ( $\chi^{2}$ test) or Fisher exact test, as appropriate. Kaplan-Meier survival plots for SVZ involvement were also performed. Finally, the predictive value of the SVZ was tested with multivariate linear regression and binary logistic regression analysis for OS and long-term survival endpoints, respectively, adjusting the associations for common confounders (age, EOR, KPS, IDH1/2 mutation and MGMT promoter status). Statistical analyses were performed with SPSS software (IBM,New York, USA, version 24.0). Differences were regarded as significant at $\mathrm{p}<0.05$. Significance values were marked in the tables.

\section{Results}

\section{Patient characteristics}

A total of consecutive 208 patients with primary GB were included in this study. The mean age was $62.9( \pm 12.26)$ years. In our study group, GBs were more common in men $(\mathrm{n}=118 ; 56.7 \%)$ than in women $(\mathrm{n}=90 ; 43.3 \%)$. Performed EORs comprised SB $(n=46 ; 22.1 \%)$, STR $(n=65 ; 31.3 \%)$ or GTR ( $\mathrm{n}=97 ; 46.6 \%)$. The mean KPS before surgery was $78.3 \%( \pm 13.0)$; postoperatively, the mean KPS of the cohort declined to $72.9 \%( \pm 19.0)$. The MGMT-promoter methylation status was investigated in 200 (96.2\%) GB individuals whereas $82(41.0 \%)$ were methylated. IDH 1/2 mutational status was available in 195 (93.8\%) cases. Here, an IDH 1/2 mutation was determined in 6 patients with GBs (3.1\%). The mean OS was 10.2 months $( \pm 8.9)$. Regarding long-term survival, there were 15 (7.2\%) cases with two-year survival.

\section{Multifocality and SVZ involvement}

Multifocal location was determined in 77 (37\%) patients. Tumor harbored the SVZ in 128 (61.5\%) cases. The detailed 


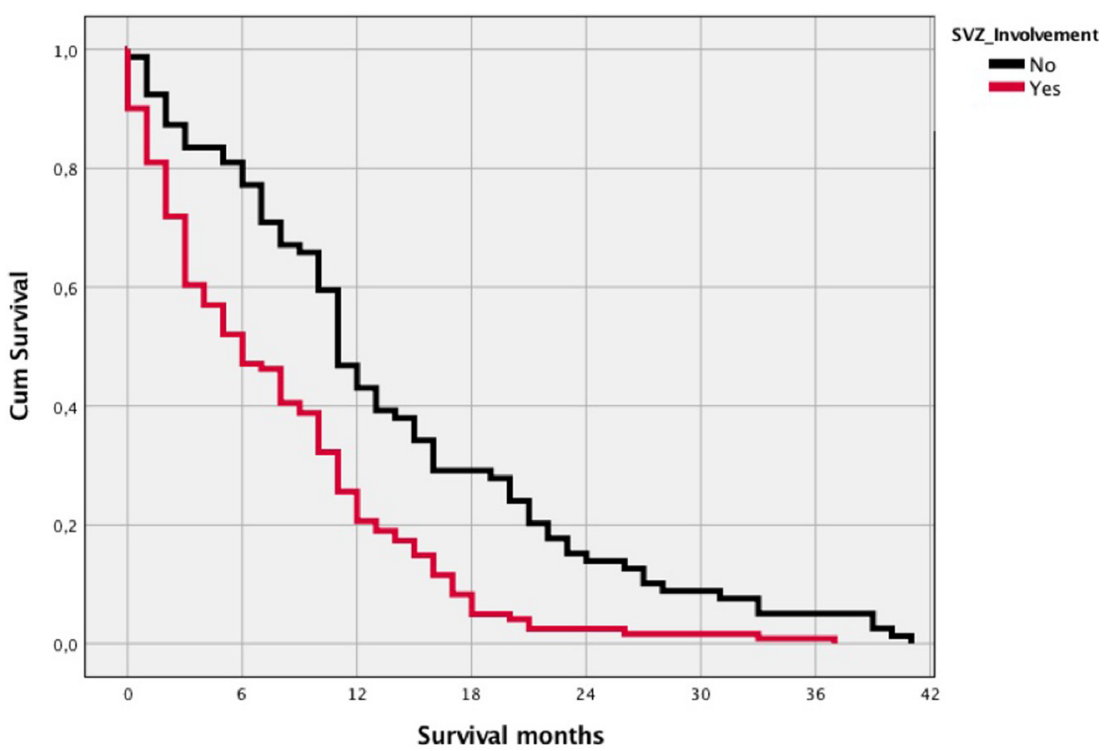

Figure 2: Kaplan-Meier survival curves with OS in months related to SVZ involvement. OS, overall survival; SVZ, subventricular zone. characteristics of the cohort with special emphasis on SVZ involvement are shown in the Table 1.

There was an association between multifocal tumor growth and SVZ involvement in our cohort ( $\mathrm{p}<0.001$, see Table 2). In addition, both radiographic parameters were associated with poorer survival of patients with GB: 8.0 $( \pm 7.4)$ vs. $11.4( \pm 9.4)$ months for multifocality ( $\mathrm{p}=0.008)$ and $7.8( \pm 7.0)$ vs. $13.9( \pm 10.1)$ months for SVZ involvement $(\mathrm{p}<0.001)$ (Figure 2). There was a significant association between SVZ involvement and worse two-year survival $(\mathrm{p}=0.001)$ which was not observed for mutifocality $(\mathrm{p}=0.179) . M G M T$ promoter status did not show any association with multifocal tumor growth $(\mathrm{p}=0.649)$ or SVZ involvement $(\mathrm{p}=0.380)$. In turn, all IDH1/2 mutated tumors showed an unifocal growth pattern $(\mathrm{p}=0.066)$ but were equally distributed with regard to SVZ $(\mathrm{p}=0.682)$.

Table 3: Influence of multifocality and SVZ involvement in extent of resection.

\begin{tabular}{lcrrr}
\hline $\begin{array}{c}\text { Extent of } \\
\text { resection }\end{array}$ & $\begin{array}{r}\text { Stereotactic } \\
\text { biopsy }(\mathrm{n}=46)\end{array}$ & $\begin{array}{r}\text { Subtotal } \\
\text { resection } \\
(\mathrm{n}=65)\end{array}$ & $\begin{array}{r}\text { Gross total } \\
\text { resection } \\
(\mathrm{n}=97)\end{array}$ & $\begin{array}{r}\mathrm{p}- \\
\text { Value }\end{array}$ \\
\hline $\begin{array}{c}\text { Unifocal } \\
(\mathrm{n}=131)\end{array}$ & $20(15.3 \%)$ & $37(28.2 \%)$ & $74(56.5 \%)$ & $<0.001$ \\
$\begin{array}{c}\text { Multifocal } \\
(\mathrm{n}=77)\end{array}$ & $26(33.8 \%)$ & $28(36.4 \%)$ & $23(29.9 \%)$ & \\
$\begin{array}{c}\text { SVZ involved } \\
(\mathrm{n}=128)\end{array}$ & $38(29.7 \%)$ & $47(36.7 \%)$ & $43(33.6 \%)$ & $<0.001$ \\
$\begin{array}{c}S V Z \text { unin- } \\
\text { volved } \\
(n=80)\end{array}$ & $8(10 \%)$ & $18(22.5 \%)$ & $54(67.5 \%)$ & \\
\hline
\end{tabular}

SVZ, subventricular zone.

\section{Impact of SVZ on surgical outcome}

GB cases with SVZ involvement revealed a significant decrease of the KPS after surgery (6.5 vs. 3.6\% in cases without SVZ, $\mathrm{p}=0.047$ ). Affection of the SVZ was also associated with higher rates of SB or STR than GTR $(p<0.001)$. Multifocal tumor characteristic was also correlated with lower EOR $(\mathrm{p}<0.001$, see Table 3$)$. Finally, multivariate analysis confirmed independent association between SVZ involvement and poor OS $(p=0.001$, see Table 4).

\section{Discussion}

This study evaluated the relationship between SVZ involvement and other characteristics of patients with GB. The presented study showed higher rate of SVZ involvement in our GB cohort. Tumors within SVZ are characterized with poorer survival, which is most likely related to higher surgical morbidity and lower EORbut not to molecular-genetic characteristics of the patients.

Radiographic contact to the SVZ is a common phenomenon in patients suffering from malignant gliomas [19]. The SVZ represents one major area of neurogenesis and is suspected to be an origin of brain cancer cells with stem cell-like properties [10, 11, 20-22]. Thus, tumors with SVZ involvement might be more proliferative and invasive. In the last decade, numerous studies have discussed that tumor localization with regard to the SVZ is associated with an increased tumor volume, multifocal tumor growth, early recurrence in patients with GB [14-17, 23-29]. This is in line 
Table 4: Multivariate analysis of predictor of OS.

\begin{tabular}{lrrrr}
\hline Parameters & RC & & 95\% Cl & p-Value \\
\hline Age & -0.157 & -0.254 & -0.060 & $\mathbf{0 . 0 0 2}$ \\
SVZ involvement & -4.182 & -6.535 & -1.829 & $\mathbf{0 . 0 0 1}$ \\
KPS preoperative & 0.083 & -0.004 & 0.170 & 0.062 \\
MGMT methylation & 2.863 & -0.004 & 0.170 & $\mathbf{0 . 0 1 5}$ \\
IDH1/2 mutation & 10.679 & 4.04 .3 & 17.316 & $\mathbf{0 . 0 0 2}$ \\
EOR & 2.213 & 0.661 & 3.766 & $\mathbf{0 . 0 0 5}$ \\
\hline
\end{tabular}

$\mathrm{Cl}$, confidence interval; EOR, extent of resection; KPS, Performance Status Scale; RC, regression coefficient; SVZ, subventricular zone.

with our data that patients with SVZ involvement were associated with shorter OS.

Consistent with previously published reports $[16,25$, 30], there was a high coincidence between multifocality and SVZ involvement in our cohort. The significant incidence of SB in cases with SVZ involvement (38/46, 82.6\%) and their association with higher rate of multifocal growth pattern $(63 / 77,81.8 \%)$ in our data could be the main reason for a decision of biopsy with consecutive lower survival rate.

Diagnosis of malignant glioma is currently based on histologic and molecular features [1]. Thus, we also investigated the relationship of $M G M T$ promoter methylation and IDH1/2 mutation status with multifocal tumor growth and tumor contact to the SVZ. MGMT promoter status was not associated with location or multifocality, consistent with previously published reports [31, 32]. Former findings from Pińa Batista et al. [33] reported a minor incidence of IDH1/2 mutated GB with SVZ involvement ( $\mathrm{n}=5,11.9 \%)$ and a major incidence of $I D H 1 / 2$ mutated GB distant to the SVZ ( $\mathrm{n}=37,88.1 \%$ ). Interestingly, all IDH1/ 2 mutated tumors showed an unifocal tumor growth pattern in our cohort. The absence of IDH 1/2 mutated tumors in multifocal GBs in our cohort could be explanatory one of the reasons for a better prognosis [34]. Hitherto, an equal amount of $I D H$ 1/2 mutated tumor was observed regarding to SVZ involvement. Here, the number of patients with $I D H 1 / 2$ mutations is probably too low to show a significance.

\section{Conclusion}

Negative impact of SVZ on GB outcome might be related to lower EOR, higher surgical morbidity and higher rates of multifocality but not to IDH1/2 mutation and MGMT promoter methylation status. Further studies are required to elucidate molecular markers relevant for tumor growth patterns and to optimize the treatment strategies of patients with BB and SVZ involvement.
Research funding: None declared.

Author contributions: All authors have accepted responsibility for the entire content of this manuscript and approved its submission.

Competing interests: Authors state no conflict of interest. Informed consent: Informed consent was obtained from all individuals included in this study.

Ethical approval: Research involving human subjects complied with all relevant national regulations, institutional policies and is in accordance with the tenets of the Helsinki Declaration (as revised in 2013) and has been approved by the local ethic committee of the University Duisburg-Essen, Germany, according to protocol number 15-6504-BO.

\section{References}

1. Louis DN, Perry A, Reifenberger G, von Deimling A, FigarellaBranger D, Cavenee WK, et al. The 2016 world health organization classification of tumors of the central nervous system: a summary. Acta Neuropathol 2016;131:803-20.

2. Stupp R, Brada M, van den Bent MJ, Tonn JC, Pentheroudakis G. High-grade glioma: ESMO clinical practice guidelines for diagnosis, treatment and follow-up. Ann Oncol 2014; 25 : 93-101.

3. Gerber NK, Goenka A, Turcan S, Reyngold M, Makarov V, Kannan $\mathrm{K}$, et al. Transcriptional diversity of long-term glioblastoma survivors. Neuro Oncol 2014;16:1186-95.

4. Hegi ME, Liu L, Herman JG, Stupp R, Wick W, Weller M, et al. Correlation of 06-methylguanine methyltransferase (MGMT) promoter methylation with clinical outcomes in glioblastoma and clinical strategies to modulate MGMT activity. J Clin Oncol 2008; 26:4189-99.

5. Yan H, Parsons DW, Jin G, McLendon R, Rasheed BA, Yuan W, et al. IDH1 and IDH2 mutations in gliomas. N Engl J Med 2009;360: 765-73.

6. Nieder C, Petersen S, Petersen C, Thames HD. The challenge of p53 as prognostic and predictive factor in gliomas. Cancer Treat Rev 2000;26:67-73.

7. Singh SK, Hawkins C, Clarke ID, Squire JA, Bayani J, Hide T, et al. Identification of human brain tumour initiating cells. Nature 2004;432:396-401.

8. Di Carlo DT, Cagnazzo F, Benedetto N, Morganti R, Perrini P. Multiple high-grade gliomas: epidemiology, management, and outcome. A systematic review and meta-analysis. Neurosurg Rev 2017;42:263-75.

9. Gil-Perotin S, Marin-Husstege M, Li J, Soriano-Navarro M, Zindy F, Roussel MF, et al. Loss of p53 induces changes in the behavior of subventricular zone cells: implication for the genesis of glial tumors. J Neurosci 2006;26:1107-16.

10. Holland EC, Celestino J, Dai C, Schaefer L, Sawaya RE, Fuller $\mathrm{GN}$, et al. Combined activation of Ras and Akt in neural progenitors induces glioblastoma formation in mice. Nature 2000;25:55-7. 
11. Zhu Y, Guignard F, Zhao D, Liu L, Burns DK, Mason RP, et al. Early inactivation of $\mathrm{p} 53$ tumor suppressor gene cooperating with NF1 loss induces malignant astrocytoma. Cancer Cell 2005;8:119-30.

12. Duan S, Yuan G, Liu X, Ren R, Li J, Zhang W, et al. PTEN deficiency reprogrammes human neural stem cells towards a glioblastoma stem cell-like phenotype. Nat Commun 2015;6:10068.

13. Curtis MA, Low VF, Faull RL. Neurogenesis and progenitor cells in the adult human brain: a comparison between hippocampal and subventricular progenitor proliferation. Dev Neurobiol 2012;72: 990-1005.

14. Adeberg S, Bostel T, König L, Welzel T, Debus J, Combs SE, et al. A comparison of long-term survivors and short-term survivors with glioblastoma, subventricular zone involvement: a predictive factor for survival?. Radiat Oncol 2014;9:95.

15. Jafri NF, Clarke JL, Weinberg V, Barani IJ, Cha S. Relationship of glioblastoma multiforme to the subventricular zone is associated with survival. Neuro Oncol 2013;15:91-6.

16. Lim DA, Cha S, Mayo MC, Chen MH, Keles E, Van den Berg S, et al. Relationship of glioblastoma multiforme to neural stem cell regions predicts invasive and multifocal tumor phenotype. Neuro Oncol 2007;9:424-9.

17. Chaichana KL, McGirt MJ, Frazier J, Attenello F, Guerrero-Cazares $\mathrm{H}$, Quinones-Hinojosa A. Relationship of glioblastoma multiforme to the lateral ventricles predicts survival following tumor resection. J Neuro Oncol 2008;89:219-24.

18. Alcantara Llaguno SR, Parada LF. Cell of origin of glioma: biological and clinical implications. Br J Cancer 2016;115: 1445-50.

19. Bohman LE, Swanson KR, Moore JL, Rockne R, Mandigo C, Hankinson T, et al. Magnetic resonance imaging characteristics of glioblastoma multiforme: implications for understanding glioma ontogeny. Neurosurgery 2010;67:1319-27. discussion 1327-8.

20. Goffart N, Kroonen J, Di Valentin E, Dedobbeleer M, Denne A, Martinive $P$, et al. Adult mouse subventricular zones stimulate glioblastoma stem cells specific invasion through CXCL12/CXCR4 signaling. Neuro Oncol 2014;17:81-94.

21. Goffart N, Lombard A, Lallemand F, Kroonen J, Nassen J, Berendsen $\mathrm{S}$, et al. CXCL12 mediates glioblastoma resistance to radiotherapy in the subventricular zone. Neuro Oncol 2016;19:66-77.

22. Gollapalli K, Ghantasala S, Kumar S, Srivastava R, Rapole S, Moiyadi A, et al. Subventricular zone involvement in Glioblastoma - a proteomic evaluation and clinicoradiological correlation. Sci Rep 2017;7:1449.

23. Chen L, Guerrero-Cazares H, Ye X, Ford E, McNutt T, Kleinberg L, et al. Increased subventricular zone radiation dose correlates with survival in glioblastoma patients after gross total resection. Int J Radiat Oncol Biol Phys 2013;86:616-22. 15.

24. Chen L, Chaichana KL, Kleinberg L, Ye X, Quinones-Hinojosa A, Redmond K. Glioblastoma recurrence patterns near neural stem cell regions. Radiother Oncol 2015;116:294-300.

25. Barami K, Sloan AE, Rojiani A, Schell MJ, Staller A, Brem S. Relationship of gliomas to the ventricular walls. J Clin Neurosci 2009;16:195-201.

26. Evers P, Lee PP, DeMarco J, Agazaryan N, Sayre JW, Selch M, et al. Irradiation of the potential cancer stem cell niches in the adult brain improves progression-free survival of patients with malignant glioma. BMC Cancer 2010;10:384.

27. Lee P, Eppinga W, Lagerwaard F, Cloughesy T, Slotman B, Nghiemphu PL, et al. Evaluation of high ipsilateral subventricular zone radiation therapy dose in glioblastoma: a pooled analysis. Int J Radiat Oncol Biol Phys 2013;86:609-15. 15.

28. Mistry AM, Hale AT, Chambless LB, Weaver KD, Thompson RC, Ihrie RA. Influence of glioblastoma contact with the lateral ventricle on survival: a meta-analysis. J Neuro Oncol 2016;131: 125-33.

29. Young GS, Macklin EA, Setayesh K, Lawson JD, Wen PY, Norden AD, et al. Longitudinal MRI evidence for decreased survival among periventricular glioblastoma. J Neuro Oncol 2011;104:261-9.

30. Larjavaara S, Mäntylä R, Salminen T, Haapasalo H, Raitanen J, Jääskeläinen J, et al. Incidence of gliomas by anatomic location. Neuro Oncol 2006;9:319-25.

31. Ellingson BM, Cloughesy TF, Pope WB, Zaw TM, Phillips H, Lalezari S, et al. Anatomic localization of 06-methylguanine DNA methyltransferase (MGMT) promoter methylated and unmethylated tumors: a radiographic study in 358 de novo human glioblastomas. Neurolmage 2011;59:908-16. 16.

32. Zhang T, Wang Y, Fan X, Ma J, Li S, Jiang T, et al. Anatomical localization of p53 mutated tumors: a radiographic study of human glioblastomas. J Neurol Sci 2014;346:94-8.

33. Pińa Batista KM, Vega IF, de Eulate-Beramendi SA, Morales J, Kurbanov A, Asnel D, et al. Prognostic significance of the markers IDH1 and YKL40 related to the subcentricular zone. Folia Neuropathol 2015;53:52-9.

34. Lin CA, Rhodes CT, Lin C, Phillips JJ, Berger MS. Comparative analyses identify molecular signature of MRI-classified SVZ-associated glioblastoma. Cell Cycle 2017;16:765-75.

Supplementary Material: The online version of this article offers reviewer assessments as supplementary material (https://doi.org/ 10.1515/iss-2020-0011). 